\title{
AN EMPIRICAL INVESTIGATION OF FINANCIAL RISK MANAGEMENT ON FINANCIAL PERFORMANCE OF COMMERCIAL BANKS
}

\author{
Jowhar Massoudie \\ E-Mail Id: jowhar.massoudie@gmail.com \\ Faculty of Economics, Kardan University, Afghanistan
}

\begin{abstract}
This research paper assesses the influence of financial risk management on financial performance of commercial banks in Nangarhar province of Afghanistan. The data collected through questionnaire, which is adopted from different authors. The multiple regression analysis (Ordinary Least Square) technique was utilized to obtain the results. The random sampling technique used to acquire the data. The main results of the study show that financial risk management has a positive and statistically significant effect on financial performance of commercial banks. One-unit rise would lead commercial banks to rise their financial performance. Similarly, the study portrayed that cash management has a positive and statistically significant effect on financial performance. One-unit rise would lead commercial banks to rise their profitability. The study recommend that commercial banks have to pay high attention in managing the distinct sort of risks to rise their profitability.
\end{abstract}

Keywords- Financial Risk Management, Financial Performance, Nanagarhar.

\section{INTRODUCTION}

Financial management refers to the process of managing financial resources of the Commercial Banks, Including management decisions about accounting and financial reporting, forecasting, and budgeting, as well as capital budget decisions, which includes the decision whether to rent or buy, and whether to give debt or justice (Demira, 2013). Demira (2013) further pointed out that it is financial management framework includes processes, systems, internal controls and related actions. How to manage its income, costs, assets, liabilities and probabilities.

It also includes its systems for risk management and financial and operational oversight performance, including budget performance and report of these functions, inside and out the outside at the global level, financial management has been investigated by various experts. Ahmad, Babur and others Kashiyev (2010) conducted a study on financial management methods and their impact on the Commercial Banks performance. This study measured the relationship between Commercial Bank performance and financial risk management practices like capital structure decision, dividend policy, investment evaluation techniques, and management of working capital and evaluation of financial performance. The company's sample section includes 40 active companies in Pakistan, related to various sections are listed in Karachi Stock Exchange. A questionnaire that was identified through the company profiles and references. The results showed positive and meaningful relationship between financial performance and financial risk management practices.

Mungai (2013) has a case study in order to identify the relationship between the management of labour capital and financial performance of private hospitals in Kenya. The purpose of this study was to review the relationship between labour capital Private financial management and performance Hospitals in Kenya. This study was identify the positive relationship to the management of labor capital. This means that profitability is rising and increase in inventory and decrease on average payable account with decreasing with increase average accounts payable. The study concluded that management must continue to manage investing in a more efficient way. It always affects profitability and management effectiveness. Demira (2013) claims to be there some financial management measures that essential for the healthy performance of each community commercial Banks. Some of the actions listed in the study was a budgeting process, financial reporting and internal controls. So it's budgeted and critical activity for these Commercial Banks to these are financial management practices. It is vital for any Commercial Banks to enhance their higher education is recognized as a dignity.

An element of development in which it is developing countries should work with them if they are interested in it progress in the world that affects knowledge and race in the competition (Mange, 2013). He noted that university education is a pivotal pillar for human development around the world. Being Kenya among the developing countries in avoid increasing the level of education number of universities. The number of state-run universities has increased by itself the number of financial management in Commercial Banks but worried about funding when available.

It is needed and they are obtained and used the most effective and effective way to benefit citizens (Waddle, 2000). Financial management is the requirements of the measures can be considerable at public university institutions.

DOI Number: https://doi.org/10.30780/IJTRS.V05.I08.002

pg. 10

www.ijtrs.com

www.ijtrs.org 


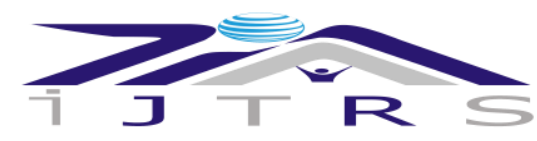

\section{International Journal of Technical Research \& Science}

Management move the funds in relation to the budget. It is essential for academic institutions performance. But experience shows that public financial management processes. Scientific institutions are usually weak and under the conditions of scarce resources throughout the country, due to the ever-increasing development plan activities that can be spent on these funds. Every individual or employee in the Commercial Banks has different values and beliefs that he has works with them whenever he joins the Commercial Banks, he persuades himself to make himself

The culture of the Commercial Banks knows whether it comes with them or not. Culture has been studied to examine the interaction of the Commercial banks process. The Commercial Banksal culture is deeply affects employee performance, which can increase productivity and improve Commercial banks performance. Managing effective management change is a business change so that executive leaders, directors and front line employees. To succeed in process, technology and commercial banks changes required. The purpose of Changing management is that these business changes are quickly trying to improve avoiding the Commercial Banks's performance by minimizing the impact on productivity un necessary turnover or loss of valuable employees, eliminating any undesirable impact on them customers and achieve the desired business results as soon as possible. Features commercial banks change is mainly classified in two dimensions: Radical versus Preventive response changes and changes. Nadler and Toshman (1999) refer to this Radical changes as changes affecting the whole system of the Commercial Banks It basically changes the definition of an Commercial Banks or changes its main framework, including strategy, structure, people, processes and (in some cases) core values. Many writers (Maurer, 1996, Waddell and Sohal, 1998) are based on the failure of many of the change initiatives.

It can be changed in resistance. Resistance is a phenomenon that affects the process of change delaying or lowering its start, preventing or preventing its implementation, and increasing its costs and generally reducing commercial bank performance (Ansoff, 1990). At on the other hand, resistance is any kind of behaviour that tries to maintain the status quo and thus avoid change (Maurer, 1996; Rumelt, 1995). Resistance is also considered as a source of information; it's not that useful to learn how to create a successful process. The negative concept as it can change directors some aspects that do not correctly illustrate Is in the process of change (Waddell and Sohal, 1998). Warrilow, (2010) refers to change management strategies as approved techniques to effectively manage change in the environment.

It changes the dynamics to take the change and direct it to the positive side of the contribution of a specific Commercial Banks before the adoption of the strategy, the Commercial Banks must know its strength and weakness, the needs of customers and the nature of the environment in which it is the work SWOT analysis can be used to evaluate the Commercial Banks's performance against a set of internal and external comparisons (Camp 1999). Along this understanding human resources are essential for Commercial Banks, also a human resource management function. Rise in the Commercial Banks hierarchy. The goal of human resource management is to be sure that the Commercial Banks has a skilled, committed and motivated workforce. This means that they will carry out steps to assess and meet the needs of the future people and to improve and improve it.

The intrinsic capacity of people to participate, potential, and job capability with presentation learning and continuous development opportunities. This includes hiring operations and selection methods, management development and educational activities related to needs Business (Michael, 2008). Strategic human resource management (SHRM) is a relatively representative one new developments in human resource management. SHRM is worried about this the role of human resources management systems in corporate performance, especially with focus Human resource solidarity as a means to gain competitive advantage. Commercial Banks are Awareness of how successful human resource policies and practices can increase performance. In various fields such as productivity, quality and financial performance. Human resources management function constantly encounters quarrels in justifying its position in Commercial Banks. At good times when there is enough money, companies can easily pay for training, staff, Rewards and employee participation systems, but when faced with financial problems, such as Human Resources and financial management.

\section{RESEARCH GAP}

Systems receive the fastest offers. Many Commercial Banks face an unstable market situation in order to creating and maintaining competitive advantage in this kind of environment, the Commercial Banks must continuously improve your business performance. Commercial Banks are increasingly becoming aware about their potential financial management as a source of sustainable competitive advantage. Related to this, more and more Commercial Banks rely on measurement methods of financial management is the name of planning, guidance, supervision, Commercial Banks, and control of the monetary resources of an Commercial Banks requires the Commercial Banks of each sector. Finance to meet your daily needs, which means any activity in the Commercial Banks of the availability of finance.it is also referred to as the animal blood of any Commercial Banks.

Do you have big or small financial needs for your daily operations? The main objective from each Commercial Banks to maximize profits. Each Commercial Banks needs finance to finance it needed in the economic world. According to John Hamptors (2010), financial management is a well-organized control monetary resources to collect the correct data according to its rationale and consistency. The main objective of financial management is financial knowledge.

$$
\begin{aligned}
& \text { www.ijtrs.com } \\
& \text { www.ijtrs.org }
\end{aligned}
$$




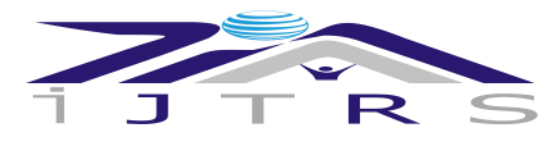

\section{International Journal of Technical Research \& Science}

A statement by a financial statement of a financial institution, such as the balance sheet and income statement. The current position of the Commercial Banks in a specific time period. Financial statements provide the use of full information about the Commercial Banks's debtor and creditors. John N. Neyer defines it "Financial Statements is the summary of the accounting of a trading company provides a balance sheet reflects assets, liabilities and capital as a specific data and statement operation results in a specified period ".

Most of the studies done in distinct to examine the effect of financial management on Commercial Banks and financial performance. However, the research gap still remain in case of Afghanistan. We would examine the impact of financial management practices in case of Afghanistan.

\section{OBJECTIVES OF THE STUDY}

$>$ To examine the effect of cash management on Commercial banks performance.

$>$ To examine the effect of credit risk management on Commercial Banks performance.

$>$ To investigate the effect of budget estimates on Commercial Banks performance.

\section{STATEMENT OF THE PROBLEM}

The impact of financial management practices on performance is one of the key issues in the field of entrepreneurship and the development of the MSE sector as illustrated by a large number of publications and studies on the subject (World Bank, 2013). According to Ahmad et al. (2011) approximately 80\% to 90\% of SMEs fail in 5-10 years. Given Kenya economy 2013 Survey, MSE performance is weak, which indicates a decline in growth. The rate rises from $5.4 \%$ in 2011 to $4.3 \%$ in 2013. Such a functional decline leads to unemployment in Kenya, resulting in social injustice and crime (RoK, 2013). Furthermore, there are ways to eliminate the distribution of bimodal from companies where $59 \%$ of MSEs, $16 \%$ of medium-sized enterprises and 23\% of corporate firms are still experiential (KPMG, 2012). Poor business performance in the MSE section has remained for a long time, especially in third world countries.

The prospect that small and medium-sized enterprises occupy a large part of the economy (Brigham, 2002). However, studies in developed countries find financial management practices strongly assist MSEs in poor business performance. Previous studies that studied MSEs, including Tushabomwe-Kazooba (2006), and Lois And Annette (2005) found that MSEs do not meet the desired expectations and if this situation has not been considered, and so the share of MSEs in the economy is likely to be affected. These studies have had unresolved inconsistencies regarding MSEs, so demanding a new study is being conducted in a developing country like Kenya and helped create. To instigate the relationship between financial management practices and MSE performance. So this study is important, not because it fills the gap, but also to determine the gap. At the local level, studies on financial management practices include: Wanyungu, (2001), which describes the methods used by small and small business research firms in research in Kenya, while Mundu (1997) conducted a study on selected financial management of small businesses in Kenya. None of these local studies has so far focused on finances management practices in small and medium companies throughout Kenya. In this context, the present study aims to investigate existing research gap with financial impact study management measures for Commercial Banks in Afghanistan. Financial management is one of several functional areas of management, but it is the success of each business. Inappropriate financial management, along with uncertainty in the business environment often makes business firms a serious problem (Lakew \& Rao, 2014).

\section{LITERATURE REVIEW}

Money related detailing was likewise found to significantly affect Project execution. This implies through money related announcing, Firms can break down their development furthermore, secure fundamental development subsidizing and also pull in new and hold outside budgetary help from new value holders. This is a basic element for enhanced Project execution. The evidence based outcome shows that as a whole financial management practices are well result given method for strengthen the firms' profitability and it plays an important function in the business Commercial Banks. These financial management practices are life blood of the business. The result of the financial management practices are higher profitability and higher market share for the Commercial Banks. So the Commercial Banks are able to improve or enhance their profitability by enhancing of the effectiveness of their financial management practices. The managing of financial resources is very crucial for boosting Commercial Banks businesses. So it can guarantee the survival and development of the business firms (Syed Ahmad Mustafa Shah, 2015). Related to the outcomes, Moore"s\&Mula"s(2003)resultsclearlyindicate increasingemphasis on money related detailing as Commercial Banks develop in business terms and advancement through the prior stages. The inevitable result for expanded money related announcing is enhanced execution of the Commercial Banks. On a similar note, Maingot and Zeghal (2006) saw that money related announcing for Firms results in enhanced Project execution. It is obvious that much has not been finished with reference to the connection between money related announcing and Project execution. The investigation hence includes huge bits of knowledge the constructive outcome of budgetary providing details regarding Project Performance. Planning practice significantly affects Project execution. This derives planning gives a system in which Firms spend their assets in the most ideal way that is available so as to acknowledge

$$
\begin{aligned}
& \text { www.ijtrs.com } \\
& \text { www.ijtrs.org }
\end{aligned}
$$




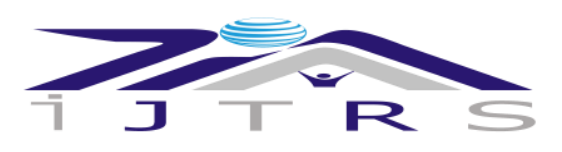

\section{International Journal of Technical Research \& Science}

benefits. All things considered, readiness of spending plans, spending ability and support of representatives in the spending procedure improve the general task execution.

In accordance with the results, Joshi et al (2003) examination of planning hones by a review of 54 medium and vast measured Commercial Banks in Bahrain found that an expansion in firm size lead firm to actualizing a more far reaching planning procedure to accomplish a superior execution. In a comparative vein, a ponder led by Chidi and Shadare (2011) in Nigeria concentrating on difficulties going up against human capital advancement in Firms found that absence of comprehension of the planning procedure was negative to the execution of the Firms. From the initial writing, it is clear that planning upgrades Project operations. The outcomes subsequently enlarge earlier discoveries that planning practice has a positive and critical impact on Project implementation.

Turyahebwa, Sunday and Sekajugo (2013) directing an examination on build up the relationship between Financial Management practices and business venture execution in western Uganda with a view to setting up a reasonable model coordinated at enhancing business operations and it was speculated that money related detailing emphatically impacts Business execution. They consider embraced a positivist (quantitative worldview) with cross sectional and corelational plans. The examination utilized a respondent example of 335 FIRMs working in Mbarara, Sheema and Bushenyi whose proprietors/directors were the unit of enquiry. Basic Equations Modeling with Investigation of Moment Structures were utilized to for measurable demonstrating. The discoveries in regard of the fundamental motivation behind the examination demonstrated that budgetary administration rehearses represented $33.8 \%$ of the difference in business venture execution. The outcomes likewise showed that working capital administration impacts profoundly since it predicts more than $22 \%$ of the change in business execution. The present investigation bolstered a multi-theoretic methodology in clarifying business venture execution in Uganda. The investigation bolsters the pecking request hypothesis in clarifying the financing of Firms together with asset based view as the hypotheses that assistance in clarifying business venture execution. The examination affirmed productive money related administration hones factor structure of watched factors and the dormant factors.

Mathuva (2009) inspected the impact of working capital administration parts on corporate benefit by utilizing an example of 30 firms recorded on the Nairobi Stock Exchange (NSE) for the periods 1993 to 2008. The discoveries from his investigation uncovered that there exists a profoundly huge negative connection between the time it takes for firms to gather money from their clients. The outcomes additionally uncovered that there exists a profoundly huge positive relationship between the period taken to change over inventories into deals (the stock transformation time frame) and benefit, and there exists an exceedingly critical positive connection between the time it takes the firm to pay its loan bosses and productivity. Similar outcomes are not at fluctuation with Uyar (2009) results which indicated measurable critical between working capital and firm execution.

Muinde (2013) led an investigation on budgetary detailing and examination hones embraced by little and medium ventures in Kenya and to set up the connection between monetary announcing and investigation hones and monetary execution in Kenya. The examination embraced an unmistakable cross-sectional research plan. The objective populace contained the best 100 Firms in Kenya for the year 2012. The analyst utilized basic arbitrary testing to choose 50 respondents. Essential information will be data assembled specifically from respondents and for this examination the scientist utilized polls. Quantitative information gathered was dissected by the utilization of enlightening insights utilizing SPSS and exhibited through rates, implies, standard deviations and frequencies. The data was shown by utilization of bar outlines, diagrams and pie outlines and in writing structure. The examination found that there is a solid positive connection between budgetary announcing, money related examination, monetary administration and administration bookkeeping and money related undertaking execution. The investigation was additionally constrained to build up the money related detailing and examination rehearses received by little and medium ventures in Kenya and to set up the connection between money related announcing and investigation hones and budgetary execution in Kenya.

\subsection{Budgeting Practices and Financial Performance}

Warue and Wanjiru (2013) evaluated factors influencing the planning forms among Small what's more, Medium Enterprises (Firms) inthehospitality industry in Nairobiecs CentralBusinessdistrict (CBD). Clear research configuration was utilized. Target populace included 98,608 of all the enlisted little ventures situated inside the CBD of Nairobi city. Stratified irregular examining was utilized in choosing the example. The populace strata depended on the idea of the business led by the FIRM in the Hospitality business. The example of 104 was shared proportionately among the 526 Firms in Hospitality industry in the CBD. Semi organized surveys of the Likert size of 1 (for solid difference) to 5 (for solid understanding) and directed to Firms administrators, was utilized to quantify the investigation factors. The information was dissected utilizing board information examination. The investigation discovers proof that modernized bookkeeping framework adds to planning process at a higher size than firm size, support of specialists, abilities and forces of directors and possession structure.

An examination directed by Chidi and Shadare (2011) in Nigeria concentrating on difficulties going up against human capital improvement in Firms in Nigeria found that planning among Firms confronted challenges by the Commercial

$$
\begin{aligned}
& \text { www.ijtrs.com } \\
& \text { www.ijtrs.org }
\end{aligned}
$$




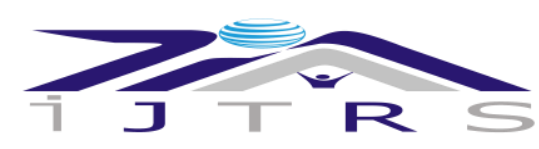

\section{International Journal of Technical Research \& Science}

Banks not taking proprietorship or not being responsible, there being a resistance as well as cooperation and an absence of comprehension of the planning procedure or what's required. This was exacerbated by the failure to meet, due dates, cushioning their spending plans/giving improbable numbers and sheer numbness of the significance of planning by the entrepreneurs. These scientists affirmed that the ability that administrators have concerning planning influence the planning procedure. The impacts of the administrators advise whether the financial plan would be executed as readied or not. In view of Mahmood (2008), examine, if the proprietors of Firms have plainly characterized association with the business, the planning procedure turns out to be more formal, advanced and precise due to the restricted impact of the proprietors. Precious stone and Khemani (2006) examined bookkeeping frameworks among Commercial Banks in the creating nations, concentrating on Africa concluded that financial plan execution and bookkeeping forms were either manual or upheld by extremely old and deficiently kept up programming applications and equipment. He found this had harming impacts on their working because of the resulting absence of solid and convenient income and use information for spending arranging, checking, use control, and announcing adversely affecting spending administration. Further, this examination found that there was ineffectively controlled duty of assets. This implied the idea of the computerization of bookkeeping influenced the planning procedure to a huge expand.

\subsection{Inventory Management Practices}

This investigation meant to experimentally analyze the effect of stock administration hone on firms' intensity and authoritative execution. Information for the investigation were gathered from 188 miniaturized scale and little ventures (MSEs) operating in the assembling sub-area and the connections and hypothesis proposed in the applied system were tried utilizing auxiliary equation modeling (SEM). The outcomes show that larger amounts of stock management practice can prompt an upgraded upper hand and enhanced Commercial Banks execution. Likewise, upper hand can have a direct, positive impact on authoritative execution. In this manner, it is suggested that policymakers, colleges, NGOs and any concerned gathering that are occupied with supporting of MSEs need to chip away at giving the important preparing and asset to advance the stock administration routine with regards to MSEs which will bring about expanding their intensity and hierarchical execution. That would upgrade their commitment to the monetary improvement of the nation. Note that, the end got from this examination may not be utilized to sum up to vast and medium scale and additionally in general segments since its center is just from the MSEs' assembling sub-part perspectives (Asefa Balda, 2018).

\subsection{Capital Budgeting}

"Capital planning," or choosing which tasks to put resources into, is both a mission and a budgetary choice in expressions of the human experience. While mission must start things out, stable associations think about the money related ramifications as a necessary piece of choosing and planning ventures.

At the point when a venture is chosen fundamentally for its monetary commitment, at that point the budgetary examination must be particularly thorough.

Expressions administrators reliably take a gander at both the mission and monetary effects of potential activities and speculations. Stable associations test their choices for the money related effect of various costs, pay, timing of costs, and different components. On the off chance that a program will proceed past its underlying subsidizing, these associations routinely and thoroughly plan how any spending development will keep on being supported. These monetary examinations enable expressions pioneers to talk about whether the distinctions in mission accomplishment legitimize the distinctions in budgetary effect, and to choose the blend of activities that strike the best equalization. A "back of the envelope" examination can be a decent initial step: the official chief at a littler association utilizes a disentangled pay and cost model to rapidly talk about with the imaginative executive the monetary effect of various projects. A thorough investigation would then be able to pursue to completely assess the most encouraging alternatives.

A task that is in accordance with mission yet is attempted fundamentally for its monetary commitment, for example, a "blockbuster" display chose to expand income, must pass a thorough budgetary investigation. Expressions pioneers need to investigate anticipated money streams from the venture and contrast them with other speculation choices to see which gives the best come back to the hazard.

For instance, is a blockbuster more beneficial, for the hazard required, than expanded interest in raising support or advertising for occasions that are more integral to mission? Net present esteem examination is the most fitting methodology for contrasting these choices; however the perfect markdown rate may not be clear. One association we met recommended a decent technique: utilize the expense of obligation, return on enrichment (an intermediary for "cost of value"), and judgment about the extra task hazard to characterize a range for the markdown rate, and afterward test how delicate the investigation is to changes over that range.

All money streams from the monetarily determined task must be considered, including expanded participation at different projects or expanded pay from a bistro or book shop produced by the consideration regarding the well known program (Zahra kharamzai, 2013).

DOI Number: https://doi.org/10.30780/IJTRS.V05.I08.002

pg. 14

$$
\begin{aligned}
& \text { www.ijtrs.com } \\
& \text { www.ijtrs.org }
\end{aligned}
$$




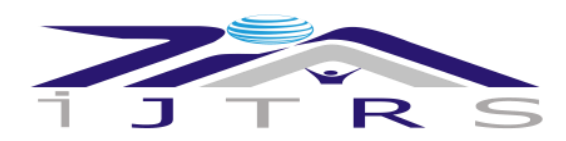

\section{International Journal of Technical Research \& Science}

\subsection{Yearly Budget Process}

Wage driven spending plans are at the core of money related administration in stable expressions associations. Zerobased spending plans made through a comprehensive, community process, and thorough testing of suppositions prompt the most precise spending plans. Further developed strategies for estimating can be valuable, and a "80/20" way to deal with these systems can work for expressions associations.

Salary driven planning, where expected pay is resolved first and cost levels are then set inside this imperative, is standard practice in every one of the associations we met. While a few associations influence their conjectures by "ordering" the earlier year's salary to up or around some rate, the more viable practice is to begin from a "zero premise" and manufacture the wage gauge from the base up. This procedure enables supervisors to assess particular presumptions and ecological changes that influence each wellspring of pay.

The greatest test in determining is obviously the estimating of individual gifts. There might be an open door for expressions associations to utilize extra anticipating systems, for example, factual techniques to assess salary changeability or the impact of particular ecological variables. These strategies can be perplexing, however a "80/20" approach ("80\% of the advantage originates from the initial $20 \%$ of the exertion") concentrated on the nuts and bolts can regularly acknowledge quite a bit of their advantage.

Nitty gritty authentic information is a key asset for precise anticipating, yet process outline and sound judgment hones are similarly essential. One association utilizes a routine with regards to anticipating "individuals in the seats," not level of limit, since "it is anything but difficult to state '80\% of limit' and feel that is achievable, however on the off chance that you take a gander at the quantity of individuals you need to get the opportunity to stroll through the way to accomplish that, you don't trust it any longer." Another association has made a spending procedure and culture in which spending plans and suppositions are tested forcefully; the outcome is that staff put more idea into their evaluations. These social methodologies are viable yet they take responsibility: an association that is updating their spending procedure to enhance joint effort among money related and masterful staff anticipates that it will take three years to make the procedure an enduring piece of the way of life.

\subsection{Budgetary Reporting and Tracking}

The spending report is the essential device for following budgetary implementation in expressions associations, and the regular establishment for any expansions to detailing. Expressions pioneers can get a more complete perspective of monetary issues by coordinating longer-term money related perspectives, fusing accounting report targets, and outlining reports to feature budgetary commitment from each program (Danial Atanful, 2018).

The spending report, demonstrating the present year's pay and cost execution against plan, is the core of execution following in expressions associations. While each spending report appears to be unique from the following, some regular upgrades help expressions pioneers recognize chances sooner and watch out for basic budgetary drivers. To start with, associations that must make monetary duties a few years into the future incorporate future figures into their spending report. These conjectures are just surmised, however strong responsibilities and "place holder" sums for other wage and costs are audited and refreshed consistently. Making a solitary report that shows both ebb and flow year and future duties helps keep a basic money related driver - the sum and danger of future responsibilities - in the budgetary exchange of officials and the board.

The accounting report is a less normal instrument for budgetary exchanges; however there are basic resource and obligation positions that do should be followed. Expressions associations can viably deal with their accounting report position by joining basic monetary record things into the spending report itself. One association we met, with critical obligation from another building, followed significant net resources account alongside obligation cost in the financial plan (Appendix, Example II).

This methodology turned their arrangement for accounting report position, dictated by their fund authorities, into an arrangement of spending objectives that were normal for staff and board individuals to examine. This training can be reached out to incorporate extra asset report targets. Be that as it may, it can't supplant the asset report itself: an intermittent depiction of budgetary position is as yet expected to check advance. An alternate spending report configuration enables expressions associations to see how programs add to or devour yearly salary.

These reports track net money related commitment by center projects, for example, presentations, and incremental exercises, for example, book shop activities, to feature the sources and employments of assets. The test here is designating shared pay or costs. One association we met gives a successful answer: instead of allotting costs, take a gander at direct pay and costs first, at that point "layer on" shared costs for the program, and after that at long last costs shared over all projects.

Maintaining a strategic distance from distributions makes spending numbers substantially less demanding to comprehend and brings execution issues into sharp core interest. By and large, this report configuration advances exchange of the connection between money related execution and mission decisions by demonstrating how particular projects and funds integrate (Leah Simon, 2017).

$$
\begin{aligned}
& \text { www.ijtrs.com } \\
& \text { www.ijtrs.org }
\end{aligned}
$$




\section{RESEARCH METHODOLOGY}

\subsection{Research Design}

According to Cooper and Schindler (2014), research design plans layout for design collection, measurement and analysis of data. They add that research design is the planning and research structure is designed to respond to research questions and helping the researcher allocate limited resources by providing important alternatives. This study is a descriptive research project. A descriptive research project is looking somewhere, time, or how on a topic (Cooper \& Schindler, 2014). In accordance with the descriptive studies of Sekaran \& Bougie (2013) may help the researcher to understand the characteristics of a group in a particular situation are systematically given in aspects of the one of the situation offers ideas for further research and, ultimately, simplifies the decisions and descriptive research design will be appropriate in this study because its purpose is evaluation of the impact of financial management on Performance in Afghanistan.

A randomized sampling scheme and a structured questionnaire based on research questions are used to collect information from respondents. The adopted questionnaire has been utilized to collect the data. The sampling technique which is utilized for the study is random sampling technique. The data has been collected and enter into the excel spreadsheet for further analysis. As it is well evident that this study is a quantitative and would provide the results. The estimation techniques that we used for the study is ordinary least square technique.

\subsection{Population}

Population is the total number of observations existed in relevant field. For example, the students of Khurasan University is the population. The targeted population is defined by Mugenda and Mugenda (2003) as a defined set individuals or objects with similar characteristics. A defined body of individuals or objects for statistical purposes (Collins \& Sensitive, 2009). The targeted population of respondents which is employed in the commercial banks in Nangarhar. This include the number of low, medium and high level managers.

\subsection{Sampling}

According to Collins and Hassey (2009), sampling is a selection process specific method for using in the decision making of institutions in the study. This study will be adopted simple random categorization and sampling. Stabilization process is part of the process in the members of the population begin with homogeneous subgroups prior to sampling. Simple random sample is a special case in which every element of the population is known and chances of equal choice (copper and acidall, 2014).

Various committees and accountants represent strata. Simple random sampling each floor was used to select the appropriate representation. Simple random sampling involves sample selection randomly from sampling frame using random tables, a computer or a generic random number generator (Saunders, Lewis and Thorne Hayle, 2003). One way to select a random sample is to assign a number to each member of the population and select the sample based on the numbers given in the randomized random number table or random numbers Created by a computer (Collins \& Hussey, 2009). The sample size of the study is 80 respondents of different level managers such as low, medium and high level mangers working in commercial banks in Nangarhar province of Afghanistan.

\subsection{Model Specification}

Following is the model which is develop for the study based on theoretical framework

$$
F P=\beta 0+\beta 1 C M+\beta 2 C R M+\beta 3 B E+\beta 4 C P+\epsilon
$$

$$
\begin{aligned}
& \text { Where, } \\
& \beta 0 \quad=\text { Intercept or constant } \\
& \beta 1-\beta 4=\text { Slope Coeeficients } \\
& \mathrm{FP} \quad=\text { Financial Performance } \\
& \mathrm{CM} \quad=\text { Cash Management } \\
& \mathrm{CRM} \quad \text { = Credit Risk Management } \\
& \mathrm{BE} \quad=\text { Budget Estimates } \\
& \mathrm{CP} \quad \text { = Cash Planning } \\
& \epsilon \quad \text { = Error Term }
\end{aligned}
$$

\subsection{Theoretical Framework}

Following is conceptual framework that identify the dependent and independent variables of the study. The above figure represents the conceptual framework of the study that identify the dependent and independent variables of the study. The dependent variable of the study is financial performance. The independent variables of the study are credit risk management, cash management, budget estimates and cash planning. 


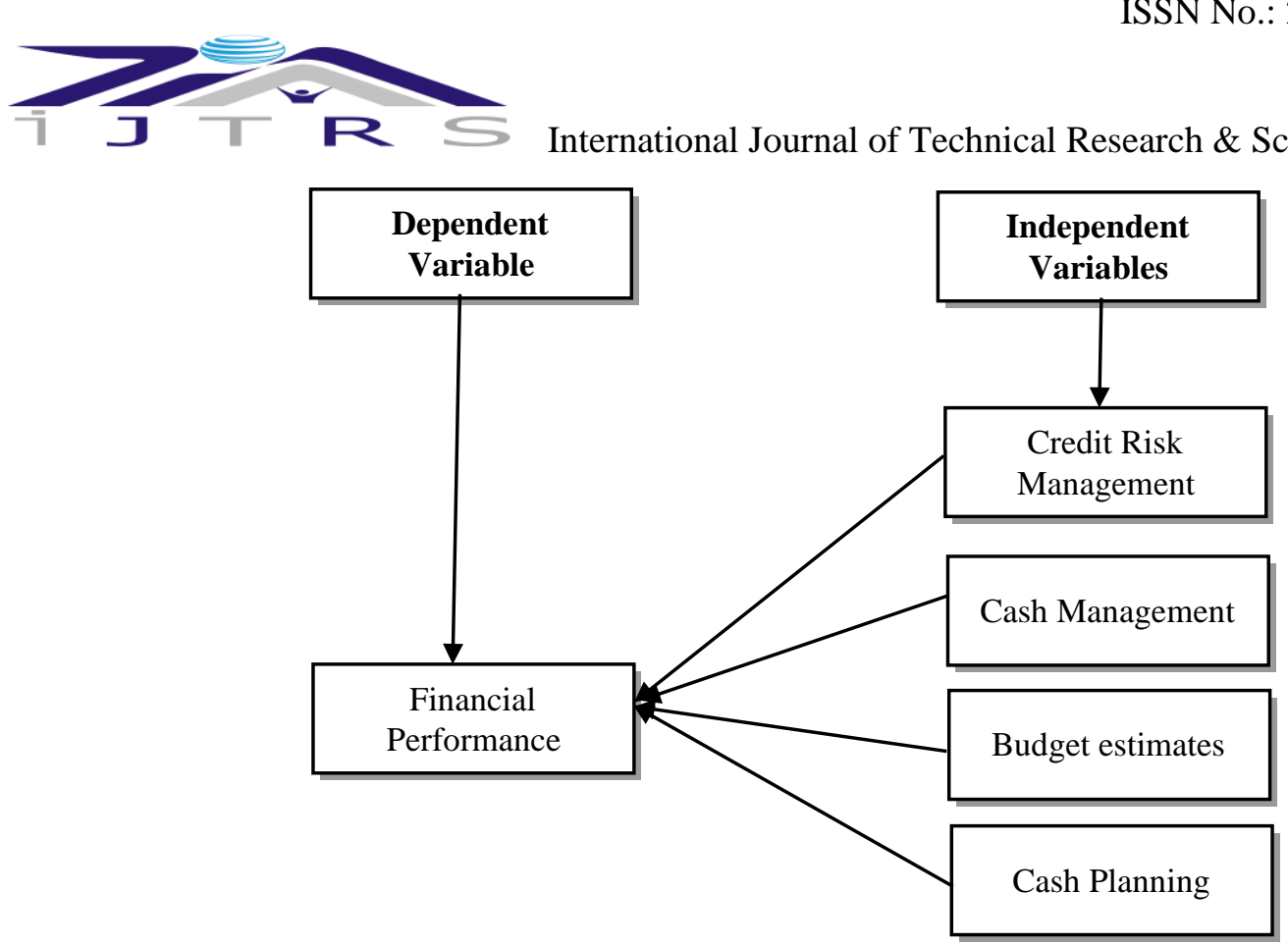

Fig. 6.1 The Conceptual Framework of the Study that Identify the Dependent and Independent Variable We examine the impact of all these independent variables on the dependent variable of the study.

\section{RESULTS AND DISCUSSION}

\subsection{Descriptive Statistics}

Following is the descriptive statistics of the study that shows the number of observation, minimum, maximum, mean and standard deviation of the study.

Table-7.1 Descriptive Statistics of the Study

\begin{tabular}{|l|c|c|c|c|c|}
\hline Variables & Observation & Mean & St. Dev & Minimum & Maximum \\
\hline Financial Performance & 150 & 0.856 & 0.058 & 0.305 & 1.032 \\
\hline Cash Management & 150 & 0.235 & 0.087 & 0.036 & 0.905 \\
\hline Credit Risk Management & 150 & 0.689 & -0.360 & 0.087 & 0.807 \\
\hline Budget Estimates & 150 & 1.025 & 0.369 & 0.809 & 1.515 \\
\hline Cash Planning & 150 & 0.897 & -0.369 & 0.256 & 1.334 \\
\hline
\end{tabular}

The summary statistics shows that financial performance which is dependent variable of the study is having 150 observation with the mean of 0.856 . The standard deviation is 0.058 . The minimum value of the variable is 0.305 and the maximum value is 1.032 . The mean of cash management is 0.235 . The standard deviation is 0.235 . The minimum value of the variable is 0.036 and the maximum value is 0.90 . The mean of credit risk management is 0.689 . The standard deviation is -0.360 . The minimum value of the variable is 0.087 and the maximum value is 0.807 . The mean of budget estimates is 01.025 . The standard deviation is 0.369 . The minimum value of the variable is 0.809 and the maximum value is 1.515 . The mean of cash planning is 0.0 .897 . The standard deviation is -0.369 . The minimum value of the variable is 0.256 and the maximum value is 1.334 .

\subsection{Correlation Matrix}

Correlation matrix identify the relation and correlation between the variables of the study. This actually show the co movement between the variables. Following table provide the correlation coefficient of the variables of the study.

Table-7.2 Correlation Matrix of the Study

\begin{tabular}{|l|l|l|l|l|l|}
\hline Variables & FP & CM & CRM & BE & CP \\
\hline FP & 1.00 & & & & \\
\hline CM & 0.57 & 1.00 & & & \\
\hline CRM & 0.38 & 0.22 & 1.00 & & \\
\hline BE & 0.62 & 0.45 & 0.51 & 1.00 & \\
\hline CP & 0.48 & 0.35 & 0.26 & 0.36 & 1.00 \\
\hline
\end{tabular}


J $\quad R$ International Journal of Technical Research \& Science

The correlation coefficient between financial performance and cash management is 0.57 . This indicatrices a positive correlation between the financial performance and cash management. This implies that an increase in cash management would enhance the financial performance of the Commercial Banks. The correlation coefficient between financial performance and credit risk management is 0.38 . This indicatrices a positive correlation between the financial performance and credit risk management. This implies that an increase in credit risk management would enhance the financial performance of the Commercial Banks. The correlation coefficient between financial performance and budget estimates is 0.62 . This indicatrices a positive correlation between the financial performance and budget estimates. This implies that an increase in budget estimates would enhance the financial performance of the Commercial Banks. The correlation coefficient between financial performance and cash planning is 0.48. This indicatrices a positive correlation between the financial performance and cash planning. This implies that an increase in cash planning would enhance the financial performance of the Commercial Banks.

\subsection{Regression Analysis}

Regression analysis shows that how all the independent variables would influence the dependant variable of the study. The following table would provide the regression result of the study.

Table-7.3 Regression Result of the Study

\begin{tabular}{|l|c|c|c|c|}
\hline \multicolumn{5}{|c|}{ Panel A: Regression Result } \\
\hline Variables & Coefficient & St.Error & t-statistics & Probability \\
\hline Cash Management & 0.025 & 0.365 & 2.89 & 0.045 \\
\hline Credit Risk Management & 0.036 & 0.045 & 2.53 & 0.036 \\
\hline Budget Estimates & 0.023 & -0.987 & 3.65 & 0.001 \\
\hline Cash Planning & 0.356 & 0.684 & 3.62 & 0.036 \\
\hline \multicolumn{5}{|c|}{0.62} \\
\hline R-Square & \multicolumn{5}{|c|}{0.04 .32} \\
\hline F-statistics & \multicolumn{5}{|c|}{0.043} \\
\hline Probability & \multicolumn{5}{|c|}{} \\
\hline
\end{tabular}

Panel A provides the coefficient of all independent variable on the dependent variable. This provide the coefficient, standard deviation, T-statistics and probability. Panel B of the study provide the diagnosis result of the study. The estimated coefficient of cash management is positive and its magnitude is 0.025 . This shows that an increase in the cash management would enhance the financial performance of the Commercial Banks. This variable is also significant highly at five percent. The estimated coefficient of credit risk management is positive and its magnitude is 0.036 . This shows that an increase in the credit risk management would enhance the financial performance of the Commercial Banks. This variable is also significant highly at five percent. The estimated coefficient of budget estimates is positive and its magnitude is 0.023 . This shows that an increase in the budget estimates would enhance the financial performance of the Commercial Banks. This variable is also significant highly at five percent. The estimated coefficient of cash planning is positive and its magnitude is 0.35 . This shows that an increase in the cash planning would enhance the financial performance of the Commercial Banks. This variable is also significant highly at five percent. Panel B of the study provides the diagnosis result of the study. R-square shows the explanatory power of the independent variable of the study. F-statistics shows the significance of overall model of the study.

\subsection{Multicullinerity}

Following table provide the multicullinerity test of the study.

Table-7.4Multicullinerity Test

\begin{tabular}{|l|c|}
\hline \multicolumn{1}{|c|}{ Variables } & VIF \\
\hline Cash Management & 3.68 \\
\hline Credit Risk Management & 8.02 \\
\hline Budget Estimates & 5.68 \\
\hline Cash Planning & 1.24 \\
\hline Accountability & 4.78 \\
\hline Human Resources & 6.35 \\
\hline
\end{tabular}

The above test that either the variables or independent variables of the study are exogenous or not. For this purpose, we ran a VIF test to examine that is there the problem of enodgeniety. As the variance inflation factor is less than 10 , this implies that there is no problem of endogneity and all the independent variables of the study are exogenous.

DOI Number: https://doi.org/10.30780/IJTRS.V05.I08.002

pg. 18

Www.ijtrs.com

www.ijtrs.org 


\section{Tine \\ International Journal of Technical Research \& Science 8. CONCLUSION AND RECOMMENDATIONS}

\subsection{Conclusion}

We investigated the impact of financial risk management on financial performance of banks. We used primary data for the study which is collected through adopted questionnaire. The obtained questionnaire was entered into excel spreadsheet for analysis. The ordinary least square estimation was utilized to obtained the estimated results. OLS is a technique which can easily obtained the efficient result by providing a propitiate solution to all problems exist in the estimation.

The result of the study shows that cash management has a positive effect on financial performance of the Commercial banks. A rise in cash management would rise the financial performance of the Commercial Banks. The result of the study shows that credit risk management has a positive effect on financial performance of the Commercial Banks. A rise in credit risk management would rise the financial performance of the Commercial Banks. The result of the study shows that budget estimates has a positive effect on financial performance of the Commercial Banks. A rise in cash management would rise the financial performance of the Commercial Banks. The result of the study shows that cash planning has a positive effect on financial performance of the Commercial Banks. A rise in cash management would rise the financial performance of the Commercial Banks. The R-square is too high that shows the explanatory power of the study. The overall model of the study is also significant highly.

\subsection{Recommendations}

Following is the recommendations of the study. Commercial Banks must manage their credit risk in order to enhance the availability of the cash and thus, enhance the profitability. Commercial Banks must try to have a cash management which would lead the organizations to enhance the profitability. Organizations must estimate their budget and this would lead the organizations to enhance their performance. Finally, organizations must try to have a cash planning which lead the organizations to enhance their profitability.

\section{REFERENCES}

[1] Abanis, T., Sunday, A., Burani, A. and Eliabu, B. (2013) Financial management practices in small and mediumenterprises in selected districts in Western Uganda. Research Journal of Finance and Accounting, 4 (2):29- 42.

[2] Abanis, T., Sunday, A., Burani, A. and Eliabu, B. (2013)Financial management practices in small and medium enterprises in selected districts in Western Uganda. Research Journal of Finance and Accounting, 4 (2):29- 42.

[3] Abor, J. (2014). The Effect of Capital Structure on Profitabilit;An Empirical Analysis of Listed Firms in Ghana. Journal of Risk Finance.

[4] Alleyne, P. and Marshall, D. (2011) An exploratory study of management accounting practices in manufacturing companies in Barbados. International Journal of Business and Social Science, 2(10): 61-70.

[5] Atrill, P. (2014). Financial Management for Decision Makers. London : Prentice Hall.

[6] Belcourt, H. (2013). Financial Management in Central and State Government. Journal of Financial Management , 4 (1) 45 - 55.

[7] Boorne, L. E., \& Kurtz, D. (2014). Contemporary Business 14th Ed. Washington DC: John

[8] Burger, A.P.J. \& Woods, G. 2008. Financial management and cost accounting module. Honours

[9] Cheserem, M. (2013). Devolved Funds From Central Government. Commission on Revenue Allocation, Retrieved from https://www.crakenya.org.

[10] Commercial Banksal performance. World Applied SciencesJournal, 9(9): 997-1002.

[11] Earl, N. (2000). How planning and capital budgeting improves SME performance. Long

[12] Ekanem,I.,(2010)."Liquidity management in small firms: a learning perspective," Journal of Small

[13] Finkler, S., A.,(2011). Financial management for public, health and not-for-profit Commercial Bankss. Upper Saddle River, NJ: Prentice Hall.

[14] Fung, L., (2012). Financial Management. London School of Economics and Political Science

[15] Gallery, N, Gallery, G, Brown, K, Furneaux, C \& Palm, C( 2011), „Financial Literacy and Pension

[16] Graham, J. R., \& Harvey, C. R. (2011). The Theory and Practice of Corporate Finance:Evidence from the Field. Journal of Financial Economics, 23 (5) 78 -89.

[17] Hedger, E., \& De Renzio, P. (2010). What do Public Financial Management assessments tell us

[18] Jain, P.K. and Yadav, Surendra S. (2007) Working capital management practices: A study of public sector

[19] Jain, P.K. and Yadav, Surendra S. (2007) Working capital management practices: A study of public sector

[20] Juul, k. (2006): Decentralization, Local Taxation and Citizenship in Senegal. Institute of Social

[21] Khadingala, G., \& Mitulla, W. (2013). Kenya Centralization Through the Devolution of Power. Washington DC: Woodrow Wilson Centre Press. 
[22] Koitaba, E., K., (2013). Analysis of factors influencing financial control practices in community based Commercial Bankss in Baringo County, Kenya. MBA Thesis, Kabarak Public sector in Mirangine Sub County, Kenya

[23] Kung, F., Huang, C., \& Cheng, C. (2013). An Examination of the Relationships among Budget

[24] Mahmood, S., (2008). Corporate governance and business ethics for FIRMs in developing countries: challenges and way forward, Islamabad, Pakistan, retrieved on 18th January from http://www.kantakji.com/fiqh/files/companies/w111.pdf

[25] Margah, M. P. (2014). Financial Management \& Control in Higher Education. New York: Routledgefalme.

[26] Mensah, B.A.K. (2012) Working capital management practices of small firms in the Ashanti Region of Ghana. International Journal of Academic Research in Business and Social Sciences, 2(1): 567-583.

[27] Mensah, B.A.K. (2012) Working capital management practices of small firms in the Ashanti Region of Ghana. International Journal of Academic Research in Businessand Social Sciences, 2(1): 567-583.

[28] Modern Analytical Tools and Financial Techniques. Interfaces, 19 (3).

[29] Mwaura, J. (2011). The effect of financial planning on the financial performance of Automobile firms in Kenya, University of Nairobi

[30] Nguyen, K. M. (2014). Financial Management Practices \& Profitability os Small \& Medium Enterprises. Journal of Financial Management, 23, 8.

[31] Ombuki, K., Arasa, R., Ngugi, P. \& Muhwezi, and M. (2014): Determinants of Procurement Power. KCA University.

[32] Programme in Public \& Development Management. Stellenbosch: School of Public Management and Planning, University of Stellenbosch Regulatory Compliance by Kenya Public Universities. Journal of Supply Chain Management. Vol.10, No.6. pp. 132-134.

[33] Saunders, M., Lewis, P. \& Thornhill, A. (2012) "Research Methods for Business Students"

[34] Stillman II, R. J. (2014). Public Administration Concepts and Cases 9th Edition. Washington: Nelson Education Limited Canada.

[35] Sulaiman, E. and Ahamed, S. (2006) Working capital management in Kerala Agro Industries Corporation Ltd. A case study. Management Researcher, 13(1): 23-39.

[36] Sulaiman, E. and Ahamed, S. (2006) Working capital management in Kerala Agro Industries Corporation Ltd. A case study. Management Researcher, 13(1): 23-39.

[37] Wambui, A. (2014). Participatory Forest Management under Devolved Governance Structure. Proceeding of the 2nd National Devolution Conference.

[38] Wanjara, S. (2015). Influence of Internal Control System on the Financial Performance of Kenya

[39] Wanyangu, D. M. (2013). Financial Management Practices of Micro \& Small Enterprises in Kenya. International Journal of Business \& Management, 6 (1) 789 - 809.

[40] Warren, S. (2015). Internal Controls, Internal Auditor. 62 (4), 69 - 73. 